\title{
Question Affix Analysis in Standard Arabic: A Minimalist Perspective
}

\author{
Abdul-Hafeed Ali Fakih ${ }^{1} \&$ Abdullah S. Al-Dera ${ }^{2}$ \\ ${ }^{1}$ Department of English, University of Ibb, Republic of Yemen \& Department of English, University of Najran, \\ Saudi Arabia \\ ${ }^{2}$ Department of English, University of Najran, Kingdom of Saudi Arabia \\ Correspondence: Abdul-Hafeed Ali Fakih, Department of English, University of Najran, Saudi Arabia. E-mail: \\ a.hafeed1@gmail.com
}

Received: September 9, 2014 Accepted: October 4, 2014 Online Published: November 25, 2014

doi:10.5539/ijel.v4n6p1 URL: http://dx.doi.org/10.5539/ijel.v4n6p1

\begin{abstract}
The study examines question affix analysis in Standard Arabic within the minimalist framework of Chomsky $(1995,1998,1999,2000$, and 2001) and shows how Standard Arabic is different from English in terms of feature strength, feature checking, and I-raising to Q (i.e., raising of the head INFL to the head COMP). The objective is to present a unified treatment of question affix analysis in Standard Arabic and illustrate to what extent possible the Arabic data interacts with Chomsky's minimalist analysis. It also demonstrates how feature licensing takes place in the right checking domains in the derivation of yes-no questions. It points out that Standard Arabic resorts to 'Merge' because it does not have auxiliary inversion, while English resorts to 'Adjunction' because of auxiliary inversion. Besides, question particles in Standard Arabic are viewed as merely morphological affixes placed sentence-initially to form yes-no questions. Furthermore, we argue that the interrogative particles in Standard Arabic have one function (that of showing interrogativity) since they do not stand for any DP, PP or AP argument. Given this, we propose that the question particles in Standard Arabic are base-generated in the head C position of $\mathrm{CP}$, since they never undergo any morpho-syntactic movement.
\end{abstract}

Keywords: Question affix, minimalist, merge, I-raising to Q, feature checking, Standard Arabic

\section{Introduction}

The syntax of head movement (auxiliary inversion) has been the main concern of generative syntactians and has witnessed major developments in the last few years, especially in the era of minimalism. This paper attempts to study and analyze question affix analysis in the derivation of yes-no questions in Standard Arabic from a minimalist perspective. The objective is to show how Standard Arabic is different from English in terms of feature strength, feature checking, and I-raising to Q on the basis of the minimalist framework of Chomsky $(1995,1998$, 1999, 2000, and 2001). It also seeks to provide a unified account of question affix analysis in Standard Arabic and demonstrate to what extent the Arabic data interacts with Chomsky's minimalist treatment.

The study is organized as follows. Section 2 provides a theoretical background of the previous accounts on the topic under discussion. It reviews the analyses of the Arab grammarians and the transformational-generative syntacticians. Section 3 presents Chomsky's (1995) minimalist treatment of the abstract question affix in English and demonstrates how Chomsky departs from the earlier treatment versions of the Q-morpheme hypothesis reviewed in section two; Chomsky's analysis is mainly based on feature checking considerations. Chomsky extends his analysis of feature checking to involve the treatment of the abstract question affix Q, assumed to be present in the D-structure of an interrogative clause. This section also presents Radford's minimalist treatment of question affix in English. Section 4 explores question affix analysis in Standard Arabic and points out the differences between English and Arabic in terms of feature licensing, raising from the head INFL to the head Comp, among other things. Following Chomsky's (1995) minimalist framework, we argue that the complementizer $\mathrm{C}$ of Standard Arabic interrogative clauses is strong and that it underlyingly contains an abstract question affix $\mathrm{Q}$, which serves as a device to distinguish the D-structure of an Arabic interrogative from that of its declarative counterpart. This section illustrates that the interrogative particles (? $a$ and $h a l$ ) in Standard Arabic are merely morphological affixes which do not stand for any DP or PP or AP argument. Furthermore, we propose that the question particles (?a and hal) (which match the meaning of any English auxiliary verb occurring in the interrogative head C (i.e., COMP) of CP) are base-generated in the head C position of $\mathrm{CP}$, since they never 
undergo any morph-syntactic raising (i.e., I-raising to Q). Given feature checking considerations, we present the justification why Standard Arabic resorts to the Merge operation (rather than Adjunction as the case in English) in the course of licensing features of a derived yes-no question. It also shows how features are checked and licensed in the Arabic derived yes-no questions.

\section{Literature Review}

\subsection{The Grammatical Analysis of the Arab Grammarians}

In the existing literature on Standard Arabic, it can be shown that the traditional and some modern Arab grammarians addressed various grammatical aspects of the grammatical analysis of questions from the point of view of their traditionally taxonomic approach to grammar which was based on structural description. The traditional Arab grammarians dealt very briefly with issues involved in the syntactic analyses of yes-no questions in Standard Arabic. They also disagreed with each other on the syntactic treatment of both the question particles (?a and hal), on the one hand, and the question words, on the other. As there was no unified account on the subject, a lot of controversy was reflected in their analyses.

In what follows, however, we demonstrate some of their analyses and the way they looked at the question particles. This can be as illustrated in (1).
1a. ?a-zayd-un kataba qiSSat-an?
Q.prtc.Zaid-nom. write-pst. story-f-sg-acc-indef.
'Is it Zaid who wrote a story?'
b. ?a-kataba zayd-un qiSSat-an?
Q.prtc.write.pst. Zaid-nom. story-f-sg-acc-indef.
'Did Zaid write a story?'

The traditional Arab grammarians (like Sibawayh (768)) argue that preposing the NP 'Zaid' in (1a) renders the sentence "ugly", i.e., pragmatically/stylistically less acceptable, while other grammarians regard it as perfectly right, since the speaker is inquiring about the NP 'Zaid', but if he is asking about the activity of writing, then preposing the verb in ( $1 \mathrm{~b})$ is more suitable.

On the other hand, many Arab grammarians (like Sibawayh (768), Ibn Malik (1203), Ibn Hisham (1211) and Ibn Aqil (1298)) and many modern Arab grammarians use the term ћuru:fu al-? istifhäm "particles of interrogation" to mean both the question particles and question words in such a way they confuse these different types of questions. In other words, their traditional approach to grammar could not account for the distinction between them. However,

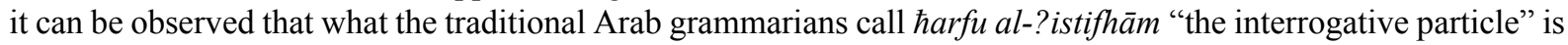
completely different from the interrogative word. In this context, we argue that the former (i.e., the interrogative particle) has only one function in that it shows interrogativity by distinguishing the interrogative sentence from its indicative counterpart. Besides, the two interrogative particles (?a and hal) match the meaning of any English auxiliary verb occurring in the interrogative head C (i.e., COMP) of CP; they are also used to head interrogative sentences of yes-no questions. The following examples in (2) illustrate the point.

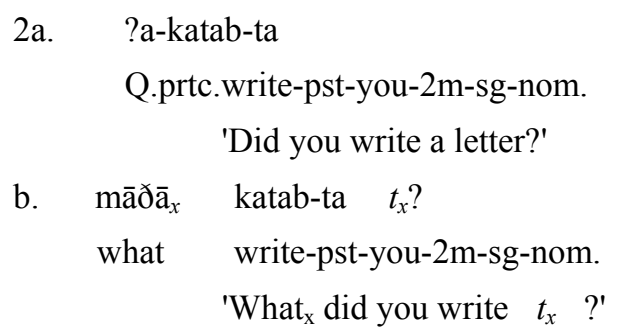

If we agree with the Arab grammarians that their ћurüfu al-?istifhāmi 'particles of interrogation' (to use their terminology) should include both the question particles and question words, then how can we account for the syntactic changes in (2b) which show the obligatorily overt movement of the object DP argument to the sentence-initial position, i.e. to [Spec, $\mathrm{CP}$ ]? The fact is that if we follow their analyses, we cannot account for how and why the question words move to the clause-initial position (i.e. to [Spec, CP]) in modern syntactic analysis. The question particles, however, cannot undergo any morph-syntactic movement, because they are viewed as merely affixes that can be placed clause-initially to form questions. Moreover, many Arab grammarians also make an incorrect generalization when they use in their syntactic analyses the term ?adawātu al-?istifhàm "devices of interrogation" instead of "interrogative particles", thus confusing both types (i.e. question particles and question 
words). We argue against their treatment by providing a piece of evidence that the "Standard Arabic word" has traditionally been divided structurally into three morpho-syntactic classes: (i) ?ismun 'a noun', (ii) fi lun 'a verb', and (iii) ћarfun 'a particle'. Thus, it is apparent that there is nothing called ?adawāt 'devices'.

\subsection{Chomsky's (1957) Analysis}

Chomsky's (1957) Syntactic Structures is not only regarded as the foundation for generative-transformational grammar, but it is still also in many respects the fundamental basis to the syntactic analysis. Chomsky's departure from the structural paradigm, following the publication of Syntactic Structures in (1957), marks the turning point of the generative-transformational paradigm. Chomsky (1957) provided a new generative look at the syntactic derivation of yes-no questions. Chomsky's morpho-syntactic analysis of yes-no question formation is exemplified by (3a-b) in which he derives the interrogative sentences (3b-d) from their corresponding declarative sentence (3a) by the application of optional transformations.

3a. John ate an apple.

b. Did John eat an apple?

c. What did John eat?

d. Who ate an apple?

According to Chomsky's analysis, sentences in (3) have the same deep structure, and therefore the question-formation rules are meaning-preserving. It is, however, observed that Chomsky's hypothesis, which derives interrogatives in (3) from their corresponding declarative counterparts, leads him to positing a single underlying structure, shown in (4), for all sentences in (3).

4. John - C - eat + an + apple $(\mathrm{NP}-\mathrm{C}-\mathrm{V}$...)

Chomsky indicates that the dashes in (4) denote that the analysis is imposed by $\mathrm{T}_{\mathrm{q}}\left(\mathrm{T}_{\mathrm{q}}\right.$ is a transformational rule proposed by Chomsky to account for yes-no questions). Furthermore, Chomsky posits two transformational rules (i.e. optional and obligatory rules) in order to derive the interrogatives in (3b-d); (3a) does not undergo such rules. For Chomsky, yes-no questions can be derived "by means of a transformation $\mathrm{T}_{\mathrm{q}}$ that operates on strings ... and has the effect of interchanging the first and second segments of these strings" (1957:63). On this basis, Chomsky proposes that there should be an ordering of rules for these transformations to apply correctly, i.e., $\mathrm{T}_{\mathrm{w}}$ must apply first to strings to which $\mathrm{T}_{\mathrm{q}}$ has already applied. $\mathrm{T}_{\mathrm{q}}$ accounts for yes-no questions while $\mathrm{T}_{\mathrm{w}}$ covers all $w h$-questions.

Let us now illustrate with examples how the transformational rules $T_{q}$ and $T_{w}$ apply in the right ordering, where $T_{q}$ has to apply first before $T_{w}$ does. Chomsky applies only an obligatory transformation to (4) to derive (5), using Chomsky's (1957:70) example to illustrate the point.

\section{5. \# John \# eat + past \# an \# apple \# ( $\longrightarrow$ "John ate an apple")}

Then Chomsky applies (5) and $\mathrm{T}_{\mathrm{q}}$ to (4) in order to derive (6).

6. past - John - eat + an + apple

By introducing the auxiliary do (i.e., as the bearer of past), Chomsky derives the following interrogative yes-no question. This can be demonstrated in (7).

7. did John eat an apple (Did John eat an apple?)

\subsection{The Q-Morpheme: The Katz-Postal Hypothesis (1964)}

Katz and Postal (1964) argue against the treatment of questions in Chomsky (1957) which shows that a question and its corresponding declarative have the same sequence of underlying P-marker(s), and yet they differ in meaning. Katz and Postal point out that questions are not genuine counterexamples as they are derived from structures containing Q-morpheme, and go on arguing that "such questions and their corresponding declaratives do not have the same sequence of underlying P-markers" (1964:79). It is thus apparent that the Q-morpheme hypothesis owes its origin to Katz and Postal's (1964) work. In their attempt to resolve some problems in Chomsky's analysis, as well as to differentiate the deep structure of a declarative from that of an interrogative, Katz and Postal (1964) hypothesize the existence of an abstract Q-morpheme in interrogative deep structures, since it triggers subject-auxiliary inversion and the fronting of $w h$-words. It is this Q-morpheme which is paraphrased as: $I$ request that you answer. Moreover, such a Q-morpheme is shown to have semantic and syntactic functions; the semantic function explicates and accounts for the illocutionary force of direct questions, and the syntactic function triggers subject-auxiliary inversion. 


\subsection{The Q-Morpheme: Baker's (1970) Analysis}

Baker's (1970) analysis of English questions aims to re-examine the evidence of Katz and Postal's (1964) proposal which states that English direct questions can be realized as sentences having in deep structures an abstract Q-morpheme. Baker (1970:197) not only argues against Katz and Postal's analysis but also attempts to offer and justify an independent position. He revises their Q-morpheme hypothesis and argues that both English direct and indirect questions contain an initial Q-morpheme in the underlying structure. He also attempts to account for the difference between declarative sentences and questions by showing that such a Q-morpheme is basic in the deep structure of questions.

Following arguments proposed in favour of positing the Q-morpheme in the clause-initial position of the deep structures of interrogative sentences in English as advocated in Katz and Postal (1964) and Baker (1970), several other arguments were raised against the Q-assumption as shown in the works of Bresnan (1970,1972), Wachowicz (1974), Kuno and Robinson (1972), Stockwell et al. (1973), Langacker (1974), Culicover (1976), Grimshaw (1990), Malone (1978), and Cheng (1991), among other linguists. These linguists have given different accounts of the Q-morpheme and have, in turn, offered a number of alternative proposals in their attempt to account for yes-no constructions.

\section{Analysis of the Question Affix in English}

\subsection{Chomsky's (1995) Minimalist Analysis of the Question Affix in English}

A closer look at Chomsky's (1995) minimalist analysis of the abstract question affix Q reveals the way Chomsky departs from the earlier treatment versions of the Q-morpheme hypothesis reviewed in section two; Chomsky's account is based on feature checking considerations. In what follows, however, we introduce his (1995) treatment of the underlying question affix Q. Chomsky's minimalist assumptions rely on 'economy principles' which aim to minimize derivations and reduce the burden of grammatical constraints and conditions imposed on the grammars of language. On the other hand, Chomsky extends his strategy of feature checking to involve the treatment of the abstract question affix $\mathrm{Q}(=[+\mathrm{wh}])$, assumed to be present in the underlying structure of an interrogative clause. On this basis, Chomsky (1995:289) proposes that the complementizer Comp in an interrogative clause of English contains an abstract question affix Q, which has a strong Q-feature. Moreover, Chomsky suggests that the Q-feature is strong in English. The following sentence in (8) illustrates the point, citing Chomsky's (1995: 289) example.

\section{Q[IPJohn gave DP to Mary]}

Furthermore, Chomsky argues that the Q-feature is plainly interpretable (i.e., it has some semantic content) and need not be checked if it is not strong. But, in case it is strong, its checking takes place before Spell-Out in order for a derivation to be constructed.

However, his observation that languages vary with regard to the strength of the Q-feature leads Chomsky to further suggest that "the strong Q-feature is satisfied by a feature $\mathrm{F}_{\mathrm{Q}}$ " (Note 1), (p. 289). As an instance in support of his argument, Chomsky points out that the abstract affix Q is strong in English and further demonstrates that, while checking features, the Q-feature has to be eliminated "by insertion of $F_{Q}$ " in its checking domain. Once $F_{Q}$ enters the checking domain of Q, it erases Q "by Merge or Move, by substitution or adjunction," (p.289). If the Merge operation is overt, the insertion of a full category $\alpha$ must be there in the checking domain of Q. If the option is substitution, $\alpha$ becomes [Spec, CP]. And if it is adjunction, $\alpha$ is an $x^{0}$ category. Chomsky asserts that in English the two cases can be illustrated in (9), using his examples.

9a. (I wonder) [CP whether Q [ he left yet ]]

b. (I wonder) [CP [C [Q if Q] [he left yet ]]

Chomsky indicates that checking domains are established by Merge in (9). In these cases whether and if remain in their base positions, but satisfy the strong feature of Q. The operations are closely analogous to raising of a wh-phrase. As far as raising is concerned, Chomsky (1995:290) derives two interrogative sentences from (8), as shown in (10).

10a. did [IP John give a book to Mary]

b. (guess) which book [IP John gave to Mary]

It can be noted that Chomsky's minimalist assumptions demonstrate that the strong feature of $\mathrm{Q}$ is checked by adjunction in (10a) in which the auxiliary did adjoins to Q, thus yielding the interpretation of a yes-no question. Following this, Chomsky suggests that $\mathrm{F}_{\mathrm{Q}}$ is interpretable and does not need to be checked. Hence, the raising of $\mathrm{F}_{\mathrm{Q}}$ in (10a), to the checking domain of $\mathrm{Q}$, eliminates the strong feature of $\mathrm{Q}$. This means that the raising of the 
question feature $\mathrm{F}_{\mathrm{Q}}$ from the head INFL position to the head complementizer position of CP checks and then erases the strong feature $\mathrm{Q}$ hosted in the interrogative complementizer. Once features are licensed, a well-derived yes-no question is produced; the auxiliary verb did raises from the head INFL position to the head Comp, thus resulting in a grammatical derivation of the construction. On the other hand, Chomsky argues that once a wh-phrase like which book and the strong feature of Q in (10) are satisfied by adjunction of INFL alone, then covert movement of the wh-feature is not necessary (as it is impossible) by economy conditions. (11) illustrates the point.

11. did John give which book to Mary

Chomsky further assumes that if (10) is embedded (where the option I-raises to Q is unavailable) then the wh-phrase can be moved overtly to the embedded [Spec, CP], yielding (12) below.

12. they remember [which book Q [John gave $t$ to Mary]]

Given that the matrix clause is interrogative, its strong Q-feature can be checked by two possible ways: I-raising or wh-movement, as demonstrated in (13).

13a. do they remember which book John gave to Mary

b. (guess) which book [they remember [ $t^{\prime} \mathrm{Q}$ [John gave $t$ to Mary]]]

(13a) illustrates an instance of I-raising (i.e., raising of INFL to COMP) and hence yields a yes-no question (with an embedded indirect question), while (13b) is an instance of $w h$-movement (given that the wh-feature is interpretable in (12) above). Furthermore, Chomsky assumes that if a language has a weak Q-feature, then a structure like that in (8) "will reach PF without essential change" (1995: 291). In such cases, Chomsky argues that the $w$-feature does not adjoin to Q. On the other hand, Chomsky points out that the strong Q cannot be inserted covertly at the root to yield the following in (14).

14. $\mathrm{Q}\left[\mathrm{DP}_{\text {subj }}\right.$ will see $\left.\mathrm{DP}_{\text {obj }}\right]$

Given (14), Chomsky does not accept that "this is a variant of $Q$ satisfied by $F_{Q}=[v]$ ", to derive a yes-no question in which I(NFL) raises to Q (hosted in the head COMP) in the overt case. He further demonstrates that Q has no phonological properties and hence must be interpreted as a wh-question. Still assuming the strength of Q in English and that covert substitution is impossible, Chomsky comes to the conclusion that "the strong feature has to be satisfied by adjunction: the strong feature of $\mathrm{Q}$ must be checked by $\mathrm{F}_{\mathrm{Q}}=[w h-]$ ", (p. 293).

However, the remaining question is: What happens when an interrogative structure contains an overt $w h$-phrase that would occur in the subject or object or adjunct position? Chomsky (1995:293f.) illustrates that, in such cases, the $w h$-feature adjoins covertly to Q; this can be illustrated in (15), using his examples (p. 293).

15a. Q[IP who will fix the car]

b. Q[IP John will fix what]

c. $\quad$ Q[iP John will fix the car how (why)]

According to Chomsky, (15a) is interpreted as a wh-question, though it has all the overt syntactic properties of IP. (15b) provides the interpretation 'what will John fix?' The last one in (15c) has to be interpreted as 'how (why) will John fix the car?'

\subsection{Radford's (1997) Minimalist Analysis of the Question Affix $Q$}

This section presents Radford's (1997) account and points out to what extent his analysis agrees or disagrees with that of Chomsky (1995). According to Radford (1997) auxiliary inversion in English questions involves an I-movement operation in which an auxiliary verb raises up from INFL to COMP. Following Chomsky's (1995) assumption that COMP in an interrogative clause is a strong head, a strong head must be filled. Given this, Chomsky proposes that the complementizer $\mathrm{C}$ in questions contains an abstract question affix $\mathrm{Q}$. Given the nature of affixes that have to be attached to suitable lexical items, Radford (1997:108) points out that "Q must be affixed either to an interrogative complementizer like if or to an auxiliary...". Radford's clause structure in (16) illustrates $\mathrm{Q}$ as an affixal question particle. 
16.

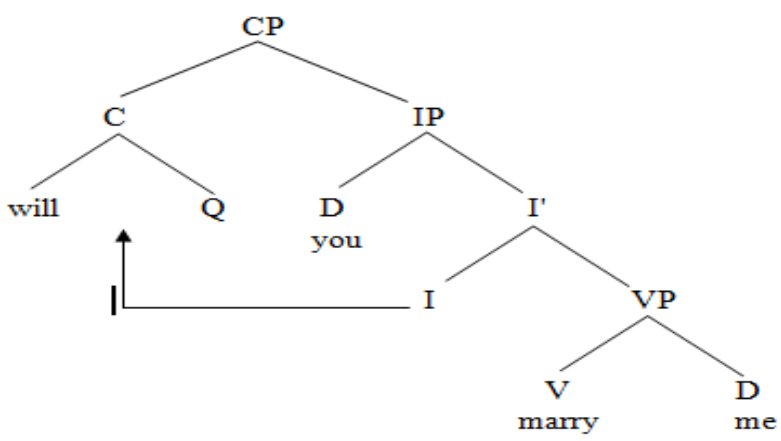

As shown in (16), the movement of the head will to the head COMP is an essential requirement for the question affix $Q$ to be attached to a suitable lexical item. However, from a cross-linguistic point of view, Radford observes that the analysis of the abstract question affix is not plausible and shows that yes-no questions in Latin were formed in which the question affix $+n e$ is used overtly. Moreover, Radford (1997: 109) assumes that "an interrogative COMP is strong and hence can lure an auxiliary from INFL to COMP", leaving unanswered the question of whether a strong interrogative COMP does or does not contain an affixal question particle Q. It can thus be implied that Radford does not assume the presence of an abstract question affix Q in COMP of interrogative clause (here, he disagrees with Chomsky's assumptions).

On the other hand, Radford (1997) raises another puzzling area of questions in English where a question formed from a statement does not contain an auxiliary and however requires the use of the (dummy) auxiliary do, as shown in (17).

17a. They know him.

b. Do they know him?

Attempting to resolve this issue, Radford assumes that the interrogative COMP is strong in present-day English, in which it has to be filled, while INFL is weak: it does not have to be filled. It is suggested that the auxiliary do is generated in order to fill COMP and further moves from INFL to COMP. In such cases, Chomsky‘s (1995) suggestion provides evidence that the dummy $d o$ is only used as a Last Resort: this condition follows from a general economy principle and it is used when there is no way of satisfying certain grammatical requirements (i.e., the necessity to fill a strong interrogative COMP). Furthermore, Radford (1997) indicates that once inverted auxiliary moves from INFL to COMP, it leaves behind a trace (or as he calls it a silent copy of itself): a constituent which has precisely the same grammatical features as its moved head. The moved constituent is the antecedent of its trace; it is this antecedent which serves to bind its empty category.

\section{Question Affix Analysis in Standard Arabic}

\subsection{Question Affix Analysis in Arabic Minimalist Terms}

It should be pointed out that there is no syntactic change in the order of the question structure while forming yes-no questions in Standard Arabic, except that the two invariant question particles ?a and hal have to be placed sentence-initially; such particles match the meaning of any English auxiliary verb occurring in the interrogative head C (i.e., COMP) of CP; they are also used to head interrogative sentences of yes-no questions.

Following Chomsky's (1995) analysis of the abstract question affix Q, let us examine the overt question particles ? $a$ and hal, heading interrogative clauses in Standard Arabic on the basis of the minimalist analysis and find out what other possible findings can be obtained, and to what extent minimalism interacts with the Arabic data. Our objective, however, is to introduce the basic minimalist analysis of the question affix Q in English to that of Standard Arabic and show whether this analysis can or cannot be applicable to a language like Standard Arabic.

Furthermore, it should be noted that the interrogative structure of yes-no questions in English is distinguished from that of Standard Arabic in that the former exhibits auxiliary inversion which undergoes syntactic movement, while the latter (Standard Arabic) does not. That is, the English auxiliary demonstrates head-to-head movement (i.e. from INFL to COMP) which does not exist in Arabic yes-no questions. The question particles in Standard Arabic are merely morphological affixes attached to the clause-initial position of Arabic interrogative yes-no questions. Let us illustrate this in (18). 


\begin{tabular}{|c|c|c|c|c|c|}
\hline $18 \mathrm{a}$. & $\begin{array}{l}\text { [IP? }{ }^{\mathrm{c}} \mathrm{t} t \bar{a} \\
\text { give-pst }\end{array}$ & $\begin{array}{l}\text { zayd-un } \\
\text { Zaid-nom }\end{array}$ & $\begin{array}{l}\text { kitāb-an } \\
\text { book-acc-inde }\end{array}$ & $\begin{array}{l}\text { li-hind-in ] } \\
\text { to-Hind-gen }\end{array}$ & \\
\hline \multicolumn{6}{|c|}{ 'Zaid gave a book to Hind' } \\
\hline b. & $\begin{array}{r}{\left[{ }_{\mathrm{CP}}[\mathrm{C} ? \mathrm{a}]-\right.} \\
\text { Q-prtc. }\end{array}$ & $\begin{array}{l}\text { [IP } ? \mathrm{a}^{\mathrm{c}} \mathrm{tā} \\
\quad \text { give-pst } \\
\text { 'Did Zaid g }\end{array}$ & $\begin{array}{l}\text { zayd-un } \\
\text { Zaid-nom } \\
\text { ve a book to } \mathrm{H}\end{array}$ & $\begin{array}{l}\text { kitāb-an } \\
\text { book-acc-indef } \\
\text { Iind?' }\end{array}$ & $\begin{array}{l}\text { li-hind-in ]] } \\
\text { to-hind-gen }\end{array}$ \\
\hline
\end{tabular}

As (18a) is an instance of a declarative sentence, (18b) is interpreted as a direct yes-no question at Spell-Out, in which the question particle $? a$ (which is the head) occupies the head C position of CP. A closer look at the difference between (18a) and (18b) reveals that $P a$ is placed sentence-initially to head questions and that it does not show any syntactic movement. We argue that the question particles in Standard Arabic have one function (i.e., that of showing interrogativity), since they do not undergo any syntactic movement. The difference between the Spell-Out of the interrogative sentence in (18b) and its LF representation is shown in (19).

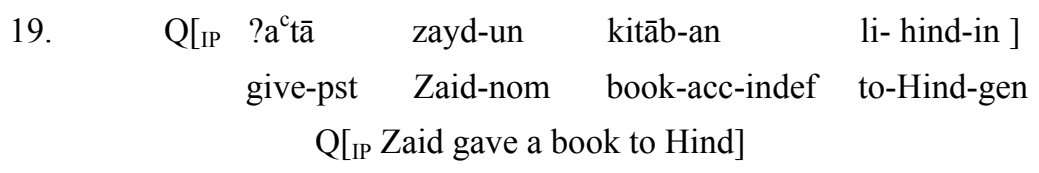

Following Chomsky's (1995) minimalist framework, we argue that the complementizer C of interrogative clauses is strong in Standard Arabic and that it underlyingly contains an abstract question affix Q. That is, the head C of CP is filled with an underlying affix $\mathrm{Q}=([+\mathrm{wh}])$. Moreover, this abstract $\mathrm{Q}$ serves as a device to distinguish the D-structure of an Arabic interrogative from that of its declarative counterpart. If we claim that the Q-feature is strong in Standard Arabic, it follows that such $\mathrm{Q}$ is satisfied by "a feature $\mathrm{F}_{\mathrm{Q}}$ " (=wh-feature). As yes-no questions in Standard Arabic do not undergo subject-auxiliary inversion, the question is: How does the abstract question affix Q in Standard Arabic get checked? and where? One possibility is to assume that the strong Q feature in Standard Arabic is licensed in its checking domain by "a feature $F_{Q}$ ". Given this, we propose that once $F_{Q}$ enters into a checking relation with $\mathrm{Q}$, the former $\left(\mathrm{F}_{\mathrm{Q}}\right)$ eliminates the strong $\mathrm{Q}$ feature by the Merge operation, where checking domains are established by Merge in Arabic yes-no questions, as shown in the examples above. In such cases, although the question particle (?a/hal) remains in its base position, it still satisfies the strong feature of Q.

Furthermore, what happens in (19) above is that the abstract affixal $Q$ is checked by the insertion of the feature $F_{Q}$ in its checking domain. Once the affixal $Q$ is erased, it disappears. In a later stage of derivation, the overt question particle ?a shows up (or emerges) in the overt syntax. Hence, a yes-no question is formed. This can be shown in (20).

$$
\begin{aligned}
& \text { 20. [ст [С ?a ]- [IP ? } \mathrm{a}^{\mathrm{c}} \mathrm{ta} \text { zayd-un kitāb-an li-hind-in ]] } \\
& \text { Q.prtc give-pst Zaid-nom book-acc-indef to-Hind-gen } \\
& \text { '[CP [C did ] [IP Zaid give a book to Hind ]]' }
\end{aligned}
$$

What should be pointed out from the preceding analysis is that an operation like I-raising to $Q$ does not exist in the syntactic analysis of the abstract affixal Q of Standard Arabic yes-no questions. This can explain why Arabic need not resort to an operation like Adjunction, Substitution or Move in the course of the derivation of yes-no questions. In such cases, we propose that Standard Arabic resorts to the Merge operation, whereby the feature $F_{Q}$ merges to the checking domain of the strong $\mathrm{Q}$ for feature checking. Once the $\mathrm{Q}$-feature is eliminated in the covert syntax, the overt question particle $? a$ merges to the head $\mathrm{C}$ position of $\mathrm{CP}$ in the overt syntax (i.e., at $\mathrm{PF}$ ), thus yielding the grammatical derivation of an interrogative yes-no question, as in (20) above. It can thus be apparent that the strong feature of the affix $\mathrm{Q}$ in Standard Arabic yes-no questions is satisfied by Merge of $\mathrm{F}_{\mathrm{Q}}$ to $\mathrm{Q}$ position subject to economy conditions, yet I-raising to Q does not exist in Standard Arabic syntax. However, if we consider the possibility that the strong $\mathrm{Q}$ feature and a wh-phrase like Payya kitäbin 'which book' are satisfied by adjunction of $\mathrm{F}_{\mathrm{Q}}$ to the checking domain of $\mathrm{Q}$ alone, as in (21) below, it follows that covert movement of the wh-feature is impossible by economy conditions.

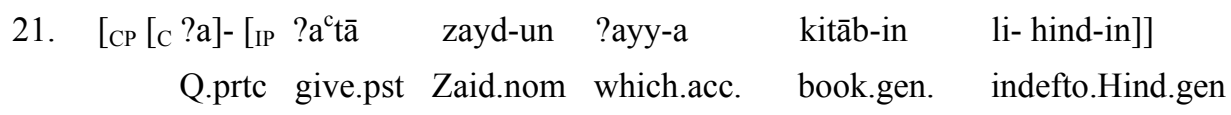

'Did Zaid give which book to Hind'

(21) can be embedded where the wh-phrase Payya kitäbin 'which book' can be moved overtly to the embedded $[\mathrm{Spec}, \mathrm{CP}]$ if the overt question particle $? a$ is lexically absent (i.e., it has to disappear), in such cases in English, the 
option I- raises to Q must be unavailable). This can be demonstrated in (22).
22. yataðakkaru
al-tullāb-u
[?ayy-a
kitāb-in $\quad Q\left[?{ }^{c}\right.$ tāa
zayd-un li- hind-in]]
remember-pres. def-students-nom.
which-acc book-gen
give-pst
Zaid-nom to-Hind-gen
'The students remember [which book Q[Zaid gave $t$ to Hind]]'

If the matrix clause in (22) is assumed to be interrogative, it follows that checking the strong Q-feature can be done by two logical ways: insertion of $\mathrm{F}_{\mathrm{Q}}$ (=wh-feature) to the checking domain of $\mathrm{Q}$ or $w h$-raising, as illustrated in (23).
23a. ?a-yataðakkaru
al-tullāb-u
?ayy-a kitāb-in
$\mathrm{a}^{\mathrm{c}} \mathrm{ta}$
zayd-un
li-hind-in
Q.prtc.remember.pres.
def.students.nom which.acc. book.gen
give.pst Zaid.nom
to.Hind.gen

'Do the students remember which book Zaid gave to Hind?'

b. (guess) Payy-a kitāb-in [yataðakkaru al-tullāb-u [t’ Q[? ${ }^{c}{ }^{c}$ tā zayd-un li-hind-in ]]]

which-acc book-gen remember.pres. def.students give.pst Zaid.nom to.Hind.gen

'(guess) which book [the students remember [ $t^{\prime} \quad \mathrm{Q}$ [ Zaid gave $t$ to Hind ]]]'

It can be noted that the preceding analysis of Standard Arabic reveals some interesting observations. For instance, the Q-feature is assumed to be interpretable (i.e., it has some semantic content since it distinguishes interrogative clauses from their declarative counterparts at LF (the Deep Structure)). Moreover, the question particles ( $P a$ and hal) are shown to be merely morphological affixes attached to the sentence-initial positions to show interrogativity. Unlike the phenomenon of I-raising to Q position (i.e., raising of INFL to COMP) in English, Standard Arabic follows a different strategy when deriving yes-no questions (i.e., the morphological affixes $P a$ and hal head interrogative sentences); this entails that they never undergo any syntactic movement. Further, Standard Arabic resorts to the operation of Merge when deriving yes-no questions, because, unlike English, it lacks DO-support; the question particle ( $(\mathrm{a} / \mathrm{hal})$ has to merge with another constituent in the clause-peripheral position (that constituent can be a verb, a demonstrative, or a pronominal...etc.).

The preceding analysis of Standard Arabic and English shows that under standard assumptions yes-no questions and wh-questions have in common the feature $[+Q]$ which marks them as questions and sets them off from declarative and other types of clauses. Wh-questions have the additional feature $[+$ wh $]$ that distinguishes them from yes-no questions. Hence, it is the feature $[+Q]$ that translates as the "question formation operator" forming the set of propositions denoted by the questions.

\subsection{Yes-No Questions in Standard Arabic}

In his investigation of a sample of 79 languages, Ultan (1969) indicates that the question particles are the most widespread technique for marking yes-no questions in the languages of the world. What comes next in his analysis of the question particles is verb movement/inversion which is essentially found among Indo-European languages.

Standard Arabic, on the other hand, exhibits yes-no questions which are introduced by the two invariant interrogative particles (?a and hal), which have to be placed at the beginning of the interrogative sentence. These two invariant particles, which never inflect for tense and Case, can be followed by either a "nominal" (i.e., verbless) or verbal interrogative sentence. In what follows, however, we show how yes-no questions appear in both "nominal" and verbal sentences.

\subsubsection{Yes-No Questions in Nominal Sentences}

By nominal sentences we mean the use of yes-no questions in verbless interrogative predicates. The following examples in (24) demonstrate how ?a and hal can be cliticized or prefixed onto demonstratives, nouns and pronominals.

24a. ?a-hāðā sadiq-u-ka ?

Q.prtc.this.m.sg. friend-nom-your

'Is this your friend?'

$\begin{array}{llll}\text { b. } \quad \text { a }-? \mathrm{ab}-\overline{\mathrm{u}}-\mathrm{ka} & \text { fi } & \text { al }-\mathrm{dā}-\mathrm{i} \text { ? } \\ & \text { Q.prtc. father-nom.your } & \text { in } & \text { def-house-loc. }\end{array}$

'Is your father in the house?
c. ?a-hiya tālib-at - un
Q.prtc.she student.f.sg.nom.indef. brilliant-f.sg.nom.indef. 
'Is she a brilliant student?'

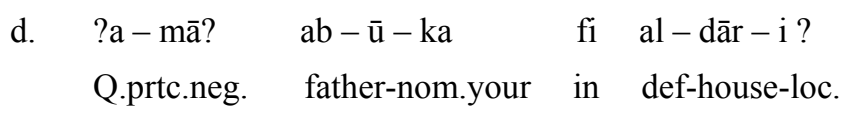

'Is your father not in the house?

The expected answer in (24a-c) is 'yes', if affirmation is required, and 'no', if negation is requested. But the situation is reversed in (24d) where the answer 'yes' shows negation while 'no' denotes affirmation. Hence, we can say that $? a$ is used to inquire about the content of both the affirmative and negative interrogatives in which the answer can be 'yes' or 'no'. On the other hand, hal is used only in affirmative questions and demands either 'yes' or 'no' as an answer, depending upon the situation. Let us illustrate this in (25).

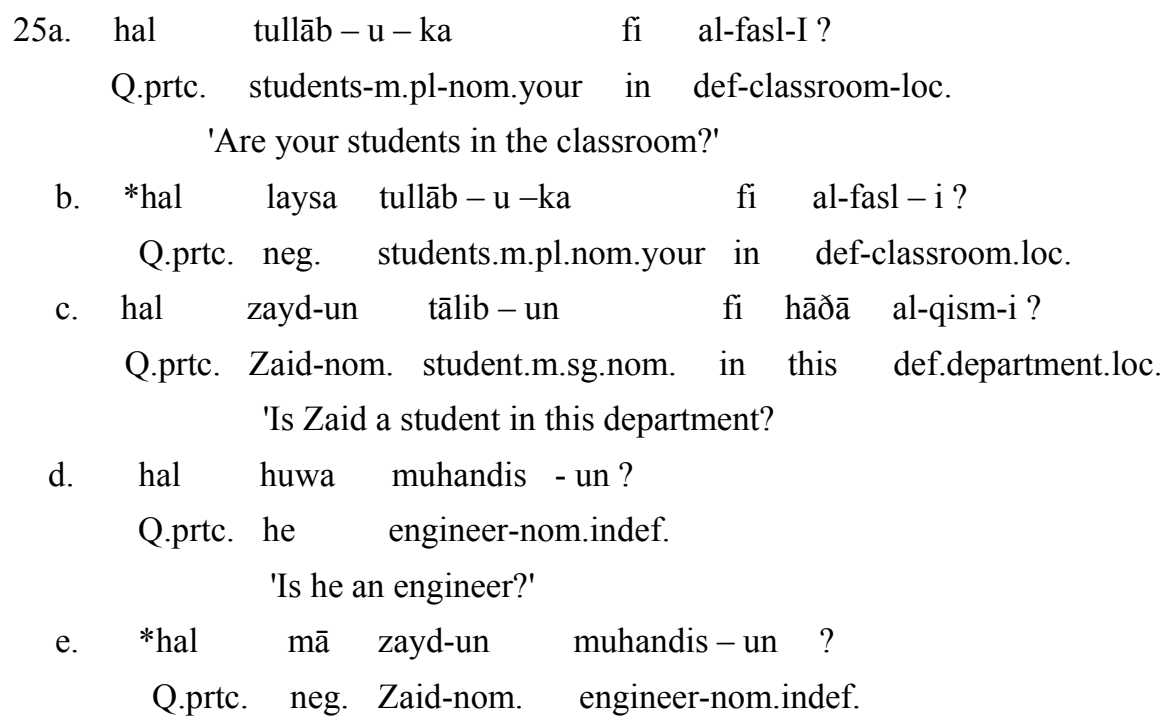

We observe that the ill-formedness of $(25 \mathrm{~b})$ and $(25 \mathrm{e})$ is due to the incorrect insertion of the negative elements lays $a$ and $m \bar{a}$ (both meaning 'not') in a question containing the question particle hal. It is thus apparent that there is a selectional restriction with regard to hal in such constructions. Given this, we assume the following syntactic representations for yes-no questions in nominal sentences in Standard Arabic. This is demonstrated in (26).
$26 \mathrm{a}$
$\left[\begin{array}{ll}\mathrm{CP} & {[\mathrm{C}}\end{array} \mathrm{?}\right.$
$\left[{ }_{\mathrm{NegP}}\left[{ }_{\mathrm{Neg}} \mathrm{NEG}\right] \quad[\mathrm{TP} \ldots \mathrm{DP}\right.$
(DP)
(PP)
(AP)]] ? (Note 2)
b. $\left[\begin{array}{ll}\mathrm{CP} & {[\mathrm{Chal}]}\end{array}\right.$
$[\mathrm{TP} \ldots$
DP (DP) (PP) (AP) ]]] ?

The representation in (26) shows that both the question particles $P a$ and hal occur sentence-initially and are followed by DP which should be followed, at least, by one of the following phrasal categories: AP or PP or DP, as shown in (25) and (26) above. The following example in (27) clarifies this.

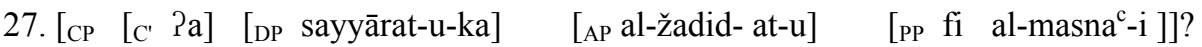
Q.prtc. car-f.sg.nom.your def-new-f.sg.nom. in def-factory-loc.
'Is your new car in the factory?'

However, there are certain cases in Standard Arabic in which the predicate clause must precede obligatorily its nominal clause; one of which is when the predicate is a prepositional phrase and the nominal clause is indefinite. (28) illustrates the point.

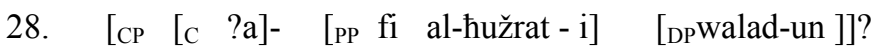
Q.prtc. in def-room-loc. boy-nom-indef.
'Is a boy in the room?'

The reason why the prepositional phrase in (28) occurs before DP is due to the indefiniteness of the latter (i.e., DP). This means that the word order given in (28) is dictated by the obligatory presence of a PP followed by an indefinite noun.

\subsubsection{Yes-No Questions in Verbal Sentences (VSO order)}

The question particles $? a$ (which we view as a bound interrogative morpheme) and hal (as a free interrogative morpheme) have to appear in the initial position of the verbal sentence. As they are used in such verbal 
constructions, they are expected to reflect agreement with the following verbs and their subject DPs but they never show that. That is, they do not reflect any grammatical agreement in terms of the three phi-features (i.e., person, gender and number). In addition, they do not inflect for tense or Case. Let us demonstrate the occurrence of $P a$ and hal before the VSO word order, which is the normal order of interrogative structures in Standard Arabic. This can be shown in (29).

$$
\text { al - rassūl - u? }
$$

Q-prtc.return.pst.m.sg. def-messenger-m.sg-nom.

'Did the messenger return?'

$$
\begin{aligned}
& \text { b. ?a-mā } \quad{ }^{c} \bar{a} d a \quad \text { al - russul }-\mathrm{u} \text { ? } \\
& \text { Q.prt.neg.(past) return-pst.m.sg. def-messengers-m.pl.nom. }
\end{aligned}
$$

'Did the messengers not return?'

c. hal ${ }^{\mathrm{c}} \overline{\mathrm{a}} \mathrm{a} a \mathrm{a}-\mathrm{rassū}-\mathrm{u}$ ?

Q.prtc. return-pst-m.sg. def-messenger-m.sg-nom.

'Did the messenger return?'
d. hal cāda
al - russul $-\mathrm{u}$ ?
Q.prtc. return-pst-m.sg. def-messengers-m.pl-nom.

'Did the messengers return?'

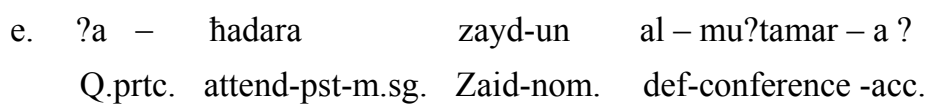

'Did Zaid attend the conference?'

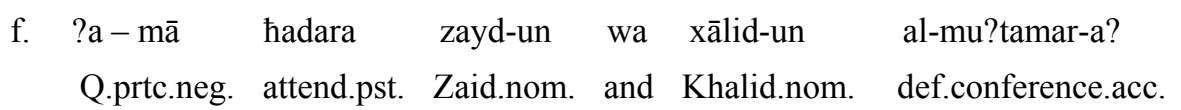

'Did Zaid and Khalid not attend the conference?'

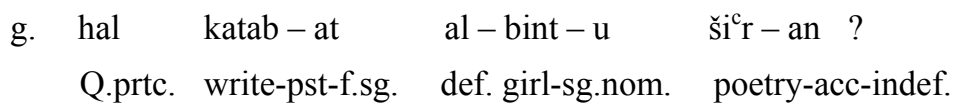

'Did the girl write poetry?'

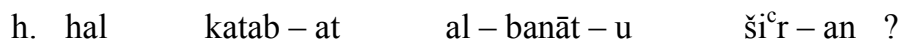

Q.prtc. write-pst-f.sg. def. girls-f.pl.nom. poetry-acc-indef.

'Did the girls write poetry?'

All the questions in (29) demand a yes-no answer. It can, however, be noted in (29) that the two question particles P $a$ and hal have nothing to do with agreement inflection shown on the verbs and their subject DPs. It is thus apparent that Standard Arabic uses these two interrogative particles as a technique for marking interrogativity, in general, and yes-no questions, in particular, as well as for distinguishing the interrogative sentence from its declarative counterpart. Given (29), we propose the following syntactic representation in (30) for yes-no questions in verbal sentences in Standard Arabic.

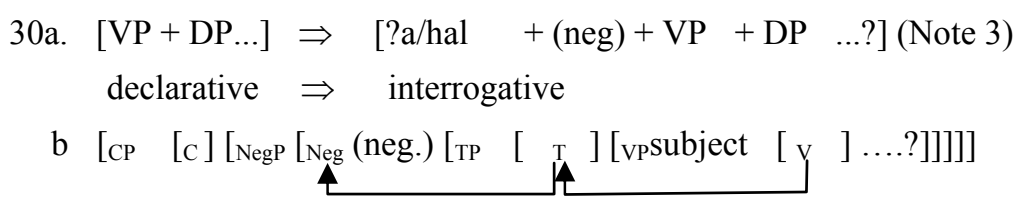

The first part of (30a) illustrates a verbal declarative clause, while the second one demonstrates its verbal interrogative counterpart which in turn spells out the sequence of the ordering of both the question particle and the negative morpheme. (30b), however, explains the $\mathrm{V}$-movement. The verb raises overtly first to $\mathrm{T}$ where the [V+T] complex is created then this complex $[\mathrm{V}+\mathrm{T}]$ moves covertly to the Neg head position. The next sub-section will explain why the subject DP moves only at LF for feature checking (thus obeying the Principle of Procrastination). Besides, (30) shows that the question particle in Standard Arabic (unlike English) is merely an affix attached to any constituent and that it has nothing to do with syntactic movement and agreement inflection, unlike the case of 
English auxiliary verb inversion in direct questions. This in turn supports our preceding proposal which suggests that in such cases Standard Arabic resorts to the Merge operation in order to satisfy the 'economy principle'.

\subsection{A Minimalist Proposal Postulating Pa and hal in the Head C Position of CP}

Given the preceding analyses of yes-no questions, the logical questions that arise here are: (i) How can we account syntactically for the question particles (?a and hal) in Standard Arabic?, and (ii) Where should such invariant question particles appear in the clause structure of Standard Arabic yes-no questions, since they do not undergo any overt or even covert syntactic raising? Given that languages vary with respect to the strength of the Q-feature, our preceding argument assumes that the Q-feature in Standard Arabic interrogative structures is strong (i.e., it has some semantic content), and that it is satisfied by "a feature F" (following Chomsky's (1995:289) analysis). Questions that arise here are: (i) How can the strong Q-feature be checked in the minimalist syntax of Standard Arabic?, and (ii) Why is it satisfied by the Merge operation rather than by Move or Adjunction? We assume that at the time of feature checking, the strong $\mathrm{Q}$ of Standard Arabic must be eliminated by insertion of $\mathrm{F}_{\mathrm{Q}}$ (= wh-feature) in its checking domain. This means that $\mathrm{F}_{\mathrm{Q}}$ enters the checking domain of $\mathrm{Q}$ in order to erase the latter by Merge (but not by Move or Adjunction); as the Merge operation is overt in Standard Arabic, a full category $\alpha$ has to be inserted in the checking domain of Q. The reason why the strong $\mathrm{Q}$ of Standard Arabic does not undergo Move or Adjunction can be explained in terms of the lack of auxiliary inversion in Standard Arabic. Adjunction demands that $\mathrm{I}$ raises to $\mathrm{Q}$ for feature checking- a morpho-syntactic operation which is not found in Standard Arabic. This implies that as $\mathrm{F}_{\mathrm{Q}}$ does not undergo raising to the checking domain of $\mathrm{Q}$, Standard Arabic, rather, follows a different operation, whereby the feature $\mathrm{F}_{\mathrm{Q}}$ merges to the checking domain of the strong $\mathrm{Q}$ for feature checking; the insertion of $\mathrm{F}_{\mathrm{Q}}$ (=wh-feature) to the checking domain of $\mathrm{Q}$ licenses its features. In other words, the Merge operation eliminates the strong feature of $\mathrm{Q}$ and in turn renders the structure fully interpretable - since all features are checked in the course of derivation. As the Merge operation is satisfied by economy conditions, the given derivation is said to converge. On the basis of this line of argument, we propose that both the question particles $P a$ and hal are base-generated in the head $\mathrm{C}$ position of $\mathrm{CP}$ due to the following morpho-syntactic reasons: (Note 4)

(i) $\quad P a$ and hal do not undergo any syntactic movement that forces them to raise overtly at PF (or even at LF).

(ii) They cannot be placed in any head position other than the head C, assuming that specifiers occur uniformly to the left in Standard Arabic.

(iii) They are merely proclitics that must occur obligatorily sentence-initially(i.e., they are affixal).

(iv) They differ from the other Standard Arabic question words in that the former ( $P a$ and $h a l$ ) cannot stand for any argument or non-argument (i.e., DP, AP, PP), whereas the latter do.

(v) They cannot be placed in [Spec, $\mathrm{CP}]$ because it is reserved for question words in Standard Arabic, and a head cannot move to the Spec position of CP, since otherwise it is a violation of the Head-to-Head Movement requirement.

(vi) The head $\mathrm{C}$ of $\mathrm{CP}$ is the right position for the representation of an interrogative sentence in a tree-diagram, since $\mathrm{CP}$ is higher than TP, as illustrated in (31).

$\begin{array}{rllll}\text { 31a. ?a / hal } & \text { xaraža } & \text { zayd-un } & \min & \text { al-bayt }-\mathrm{i} ? \\ \text { Q.prtc. } & \text { get out-pst.m.sg. } & \text { Zaid-nom. } & \text { from } & \text { def.house-loc. }\end{array}$

'Did Zaid get out of the house?'

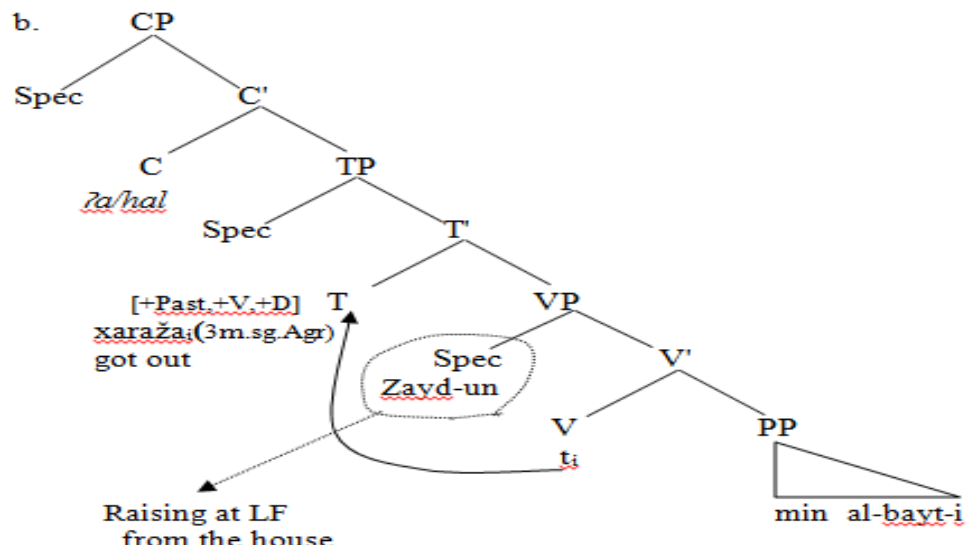


It can be shown in (31b) that the verb raises overtly to the checking domain of the head position of $\mathrm{T}$ (i.e., Tense) in order to check the categorial feature $[+\mathrm{V}]$ of the tense, since the only legitimate candidate to check the tense feature is another head, namely the verb whose overt movement to the head $\mathrm{T}$ forms the complex [V $+\mathrm{T}]$ (cf. Fakih 1999:125ff.). Once the features are raised and checked, they get eliminated in the course of derivation, given the minimalist analyses of Chomsky (1995, 1998, 1999, 2000, and 2001), Lasnik (1999), Ouhalla (1999), Benmamoun (1999, 2000) and Fakih $(1999,2006,2007 a, 2007 b$, and 2011). While feature checking, the uninterpretable inflectional features enter into agreement relation with interpretable inflectional features. What happens in (31) is that the $\Phi$-features of $\mathrm{T}$ are uninterpretable and agree with the interpretable $\Phi$-features of a nominal, thus producing noun-verb agreement in the course of derivation, following Chomsky's (2000:2-3) minimalist analysis. The agreement relation is said to remove the uninterpretable features from the "narrow syntax", a process that makes derivations converge at the LF component. Having dispensed with Agr (agreement) altogether, we assume, following Chomsky's (2000:3) minimalist analysis, that the checking operation "Agree" does hold between uninterpretable inflectional features and interpretable ones; it is under "Agree" that both types of features (uninterpretable and interpretable) in (31) above get deleted in the course of derivation. On the other hand, we assume that the failure of the subject DP in (31) to move overtly to [Spec, TP] for feature checking can be attributed to its weak D-feature, which makes its raising impossible in overt syntax. Hence, we assume that the subject DP can only move at LF for feature checking, thus obeying the Principle of Procrastination that prefers delaying movement until LF.

Given the preceding analysis, which is also represented in the clause structure in (31), a conclusion can be arrived at stressing that the Standard Arabic question particles never show any overt or even covert raising due to the reason that they are merely morphological affixes that are base-generated in the head C position of CP.

\section{Conclusion}

The study has explored the interaction between Chomsky's minimalist analysis of question affix in Standard Arabic. The application of Chomsky's minimalist framework to the Standard Arabic data has revealed interesting findings. It has pointed out that there are major differences in the question affixal Q analysis involved in the derivation of yes-no questions in English and Standard Arabic in terms of feature strength, feature checking, I-raising to Q (i.e., raising of the head INFL to the head COMP), among other morpho-syntactic properties. It has shown that in the course of feature checking English resorts to the Adjunction operation because it has auxiliary inversion which motivates I-raising to $\mathrm{Q}$ for feature licensing requirements due to the feature strength of the head INFL (that hosts an auxiliary verb as a head). In other words, the auxiliary verb adjoins to the head COMP in order to check the strong $\mathrm{Q}$ feature (hosted in the interrogative COMP), thus yielding the interpretation of a yes-no question in English.

Furthermore, it should be noted that the interrogative structure of yes-no questions in English is distinguished from that of Standard Arabic in that the former exhibits auxiliary inversion which undergoes syntactic movement, while the latter (Standard Arabic) does not. That is, the English auxiliary demonstrates head-to-head movement (from INFL to COMP) which does not exist in Standard Arabic yes-no questions. The question particles in Standard Arabic are merely morphological affixes attached to the clause-initial position of Arabic interrogative yes-no questions.

Following Chomsky's (1995) minimalist framework, we have argued that the complementizer C of interrogative clauses is strong in Standard Arabic and that it underlyingly contains an abstract question affix $\mathrm{Q}$ which serves as a device to distinguish the D-structure of a Standard Arabic interrogative from that of its declarative counterpart. Furthermore, we have proposed that the question particles ? $a$ and hal (which match the meaning of any English auxiliary verb occurring in the interrogative head $\mathrm{C}$ of $\mathrm{CP}$ ) are base-generated in the head $\mathrm{C}$ position of $\mathrm{CP}$, since they never undergo any morph-syntactic raising (i.e., I-raising to Q). Given feature checking considerations, we have argued that Standard Arabic resorts to the Merge operation in the course of licensing features of a derived yes-no question for the following reasons: (i) I-raising to Q (which involves auxiliary inversion from the head INFL to the head COMP position) does not exist in Standard Arabic, (ii) The Arabic question particles have one function(i.e., that of showing interrogativity) because they are merely morphological affixes placed sentence-initially to form yes-no questions, and (iii) Since these question particles are not part of the verb morphology and do not stand for any DP, PP or AP argument, they do not undergo any morpho-syntactic movement.

What can be pointed out from the preceding analysis is that an operation like I-raising to Q does not exist in the syntactic analysis of the question affix of yes-no questions in Standard Arabic. This can explain why Standard Arabic need not resort to an operation like Adjunction, Substitution or Move in the course of the derivation of 
yes-no questions.

\section{Acknowledgments}

The authors would like to thank the anonymous reviewer(s) for their valuable comments and suggestions on the earlier draft of this study. The study has also benefited from the IJEL editor's comments. I would also like to thank Najran University, Saudi Arabia, for supporting this study.

About the authors: Dr. Abdul-Hafeed Ali Fakih is Associate Professor of Linguistics at the Department of English, Ibb University, Yemen. He was the Dean of Center of Languages, Ibb University, Yemen. He taught linguistics in different reputed universities in Yemen and abroad. He published many papers in different international journals. He also supervised many M.A and Ph.D students. He is a member of different editorial and reviewer boards of international journals (USA, Canada, Malaysia, Finland, India, and Yemen). He is currently teaching linguistics at the Department of English, Faculty of Arts and Science, Najran University, Kingdom of Saudi Arabia.

Dr. Abdullah Al-Dera is Associate Professor of Linguistics at the Department of English, Najran University, Saudi Arabia. He is the Head of the English Department and Dean of Faculty of Arts and Science. He taught different courses in applied linguistics for more than twenty years in different Saudi universities. He published many papers in international journals. His research interests focus on borrowing, language acquisition, bilingualism, applied linguistics, and contrastive studies.

\section{References}

Bahloul, M. (1993). The copula in Modern Standard Arabic. In M. Eid, \& C. Holes (Eds.), Perspectives on Arabic Linguistics (pp. 209-230). Amsterdam: John Benjamins. http://dx.doi.org/10.1075/cilt.101.14bah

Baker, C. L. (1970). Notes on the description of English questions: The role of an abstract Q-morpheme. Foundations of Language, 6, 197-219.

Benmamoun, E. (1989). Negation, minimality, and inflectional morphology. Ms. University of Illinois.

Benmamoun, E. (1999). Arabic morphology: The central role of the imperfective. Lingua, 108, $175-201$. http://dx.doi.org/10.1016/S0024-3841(98)00045-X

Benmamoun, E. (2000). The Feature structure of functional categories: A comparative study of Arabic dialects. Oxford: Oxford University Press.

Bresnan, W. (1970). On complementizers: Toward a syntactic theory of complement types. Foundations of Language, 6, 297-321.

Bresnan, W. (1972). Theory of complementation in English syntax. Ph.D. dissertation, MIT.

Cheng, L. L. S. (1991). On the typology of wh-questions. Ph.D. dissertation, MIT.

Chomsky, N. (1957). Syntactic Structures. The Hague: Mouton.

Chomsky, N. (1991). The theory of principles and parameters. In N. Chomsky (Ed.), The Minimalist Program (pp. 13-129). Cambridge, MA.: The MIT Press.

Chomsky, N. (1995). Bare phrase structure. In G. Webelhuth (Ed.), Government and Binding Theory and the Minimalist Program (pp. 383-420). Oxford: Blackwell.

Chomsky, N. (1995). The minimalist program. Cambridge, MA.: The MIT Press.

Chomsky, N. (1998). Minimalist inquiries: The framework, Preliminary version in MIT Working Papers in Linguistics 15. In R. Martin, D. Michaels, \& J. Uriagereka (Eds.), Step by Step: Essays on Minimalist Syntax in Honor of Howard Lasnik. Cambridge, MA.: MIT Press.

Chomsky, N. (1999). Derivation by phase. Ms., Cambridge, MA.: MIT.

Chomsky, N. (2000). Minimalist inquiries: The framework, Preliminary version in MIT Working Papers in Linguistics 15. In R. Martin, D. Michaels, \& J. Uriagereka (Eds.), Step by Step: Essays on Minimalist Syntax in Honor of Howard Lasnik. Cambridge, MA.: MIT Press.

Chomsky, N. (2001). Beyond explanatory adequacy. Ms., Cambridge, MA.: MIT.

Culicover, P. W. (1976). Syntax. New York: Academic Press.

Eid, M. (1992). Pronouns, questions, and agreement. In E. Broselow, M. Eid, \& J. McCarthy (Eds.), Perspectives on Arabic Linguistics (pp. 107-143). Amsterdam: John Benjamins. http://dx.doi.org/10.1075/cilt.85.08eid 
Fakih, A. (1999). Some aspects of agreement in Arabic and English morphosyntax. Unpublished M.Phil. dissertation, University of Delhi.

Fakih, A. (2006). Case, agreement and wh-movement in Verbal constructions in Standard Arabic: A minimalist perspective. The University Researcher Journal, 13, 1-16. University of Ibb, Yemen.

Fakih, A. (2007a). Wh- and multiple wh- questions in Standard Arabic, English, and the Slavic languages and LF-representation. The University Researcher Journal, 13, 1-28. University of Ibb, Yemen.

Fakih, A. (2007b). Licensing: movement and feature checking in Standard Arabic and minimalism. Journal of King Saud University, 19, 37-54.

Fakih, A. (2011). The syntax of questions in Modern Standard Arabic: A minimalist perspective. London: Amazon/Lambert Academic Publishing.

Grimshaw, J. (1990). Argument structure. Cambridge, MA.: The MIT Press.

Ibn Aqil, B. A. (1298). [Reprinted 1964]. Sharh Ibn Aqilala al-fiyyati Ibn Malik [Ibn Aqil's Explanation to Ibn Malik's A-Rime]. Vol. II. Beirut: Daar Al-Fikr.

Ibn Hisham, A. (1211). Qatr Al-Nada waballu al-Sada [Dewdrops]. Beirut: Al-Maktaba Al- ${ }^{\text {casriyya. }}$

Ibn Malik, A. (1203). [Reprinted 1986]. Awdah al-masaalik [The Clearest Ways]. Vol. II. Beirut: DaarIhiya Al-Turaath Al- ${ }^{\mathrm{c}}$ arabi.

Katz, J. J., \& Postal, P. M. (1964). An integrated theory of linguistic description. Cambridge, MA.: The MIT Press.

Kuno, S., \& Robinson, J. J. (1972). Multiple wh questions. Linguistic Inquiry, 3, 463-487.

Langacker, R. W. (1974). The question of Q. Foundations of Language, 11, 1-37.

Lasnik, H. (1999). Minimalist analysis. Oxford: Blackwell.

Lasnik, H. (1999). On feature strength: Three minimalist approaches to overt movement. Linguistic Inquiry, 30, 197-217. http://dx.doi.org/10.1162/002438999554039

Malone, J. L. (1967). A transformational re-examination of English questions. Language, 43, 686-702. http://dx.doi.org/10.2307/411811

Ouhalla, J. (1999). Introducing transformational grammar: From principles and parameters to minimalism. Oxford: Oxford University Press.

Radford, A. (1997). Syntax: A minimalist introduction. Cambridge: Cambridge University Press. http://dx.doi.org/10.1017/CBO9781139166898

Rizzi, L. (1990). Relativized minimality. Cambridge, MA.: MIT Press.

Sibawayh. (768). [Reprinted 1973]. Al-kitāb [The Book], Part II . Cairo: Bulaq Press.

Stockwell, R. P., Schachter, P., \& Partee, B. (1973). The Major Syntactic Structures of English. New York: Holt, Rinhart, and Winston, Inc.

Ultan, R. (1969). Some general characteristics of interrogative systems. Stanford University Working Papers on Language Universals, 1, 41-63.

Wachowicz, K. A. (1974). Against the universality of a single wh-question movement. Foundations of Language, $11,155-166$.

Wahba, W. A. (1984). Wh-constructions in Egyptian Arabic. Unpublished Ph.D. dissertation, Urbana-Champaign: University of Illinois.

\section{Notes}

Note 1. $F_{Q}$ is often called the wh-feature" (Chomsky 1995: 289).

Note 2. Negation occurs only with $P a$, not with hal.

Note 3. The question particle $P a$ (but not $h a l$ ) is only used with negation.

Note 4. Eid (1992:107-43) argues that almost all modern Arabic dialects use the pronouns as a question marking device and suggests that $\mathrm{C}$ includes the question marker $\mathrm{Q}(+$ wh) which assigns a question interpretation to the structure at LF. Benmamoun (1989), however, assumes that COMP position of CP is occupied by the question particles, such as ?a of Standard Arabic, as Eid (ibid) indicates. On the other hand, Wahba (1984) generates the 
question pronoun in $\mathrm{C}$ position in her analysis of wh-constructions in Egyptian Colloquial Arabic. Moreover, Bahloul's (1993: 224-5) claim that hal is a question word is insufficiently justified. We always argue that hal is only a question particle, not a question word. Bahloul goes on to treat hal in the same way as the question word limā $\bar{a}$ 'why' and argues that both of them originate in the Spec position of CP. It is apparent that Bahloul mixes up the distribution of the syntactic position and function of the question particle hal and the interrogative word limāya 'why'. What makes him do this is that he attempts to apply Rizzi's (1990) analysis of French on Arabic, in which Rizzi indicates that there is a contrast existing between the French pourquoi 'why' and other wh-phrases; where pourquoi only occurs sentence-initially. Bahloul's (1993: 224) tree-diagram for the Arabic question types under consideration is given below in (i).

(i)

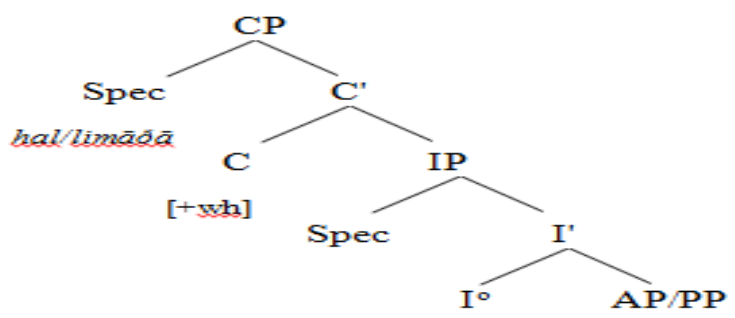

It can be observed that the preceding analyses focused only on Arabic dialects. Our analysis, however, focuses on Standard Arabic and aims to provide a formal treatment of question affix analysis in Standard Arabic based on Chomsky's minimalist framework.

\section{Copyrights}

Copyright for this article is retained by the author(s), with first publication rights granted to the journal.

This is an open-access article distributed under the terms and conditions of the Creative Commons Attribution license (http://creativecommons.org/licenses/by/3.0/). 